Check for updates

Cite this: Chem. Sci., 2019, 10, 3330

๑ All publication charges for this article have been paid for by the Royal Society of Chemistry

Received 11th November 2018

Accepted 11th January 2019

DOI: $10.1039 / \mathrm{c} 8 \mathrm{sc} 05016 \mathrm{c}$

rsc.li/chemical-science

\title{
Downsizing feature of microphase-separated structures via intramolecular crosslinking of block copolymers $\uparrow$
}

\author{
Kodai Watanabe, (D) ${ }^{a}$ Satoshi Katsuhara, ${ }^{a}$ Hiroaki Mamiya, ${ }^{\mathrm{b}}$ Takuya Yamamoto, (D) ${ }^{\mathrm{a}}$ \\ Kenji Tajima, ${ }^{a}$ Takuya Isono (D) ${ }^{* a}$ and Toshifumi Satoh (D)*a
}

\begin{abstract}
A novel strategy for downsizing the feature of microphase-separated structures was developed via the intramolecular crosslinking reaction of block copolymers (BCPs) without changing the molecular weight. A series of BCPs consisting of poly[styrene-st-(p-3-butenyl styrene)] and poly(rac-lactide) (SBS-LA) was subjected to Ru-catalyzed olefin metathesis under highly diluted conditions to produce intramolecularly crosslinked BCPs (SBS(Cl)-LAs). Small-angle X-ray scattering measurement and transmission electron microscopy observation of the SBS(Cl)-LAs revealed feature size reduction in lamellar (LAM) and hexagonally close-packed cylinder (HEX) structures in the bulk state, which was surely due to the restricted chain dimensions of the intramolecularly crosslinked SBS block. Notably, the degree of size reduction was controllable by varying the crosslink density, with a maximum decrease of $22 \%$ in the LAM spacing. In addition, we successfully observed the downsizing of the HEX structure in the thin film state using atomic force microscopy, indicating the applicability of the present methodology to nextgeneration lithography technology.
\end{abstract}

\section{Introduction}

The self-assembly of block copolymers (BCPs) can produce various periodic nanostructures depending on the volume fraction of each block $(f)$, such as lamellar, hexagonally closepacked cylinder, bicontinuous gyroid, and body-centered cubic structures. Therefore, it has attracted great interest in nanomanufacturing fields. ${ }^{1-8}$ In particular, "bottom-up" BCP lithography, in which line patterns can be fabricated on the underlying substrate using a microphase-separated thin film with $c a .10-100 \mathrm{~nm}$ features as a resist, has received substantial attention as a next-generation technology to replace the conventional "top-down" photolithography. ${ }^{9-20}$ To further advance BCP lithography, a very important requirement is to create nanostructures with shorter periodicity, i.e., smaller domain-spacing $(d)$, and thus it is a current major focus in the field of BCP self-assembly. Since the feature size of the microphase-separated structures reflects the radius of gyration $\left(R_{\mathrm{g}}\right)$ of the $\mathrm{BCP}$, the $d$ value can be decreased by reducing the degree of polymerization $(N)$. Yet, microphase separation

${ }^{a}$ Faculty of Engineering and Graduate School of Chemical Sciences and Engineering, Hokkaido University, Sapporo 060-8628, Japan. E-mail: isono.t@eng.hokudai.ac.jp; satoh@eng.hokudai.ac.jp

${ }^{b}$ Quantum Beam Unit, Advanced Key Technologies Division, National Institute for Materials Science, Ibaraki 305-0047, Japan

$\dagger$ Electronic supplementary information (ESI) available: Experimental procedures and additional data $\left({ }^{1} \mathrm{H}\right.$ NMR, SEC, IR, and DSC). See requires the product of Flory-Huggins interaction parameter $(\chi)$ and $N$ to exceed the critical value of $\chi N=10.5$ for linear symmetric diblock copolymers $(f=0.5) .^{21,22}$

A rational approach to achieve a smaller $d$ value is decreasing the $N$ value while increasing the $\chi$ value. Thus, a number of "high- $\chi$ BCPs", such as silicon-containing, ${ }^{23-28}$ metal-doped ${ }^{29-31}$ and oligosaccharide-based $\mathrm{BCPs}^{32-35}$ have been developed. However, only limited pairs of monomers are available for this approach. An alternative approach that is applicable to a wide range of polymers is reducing the $R_{\mathrm{g}}$ of $\mathrm{BCP}$ by varying the macromolecular architecture. In the pioneering work by Hawker et al., the macrocyclic BCP was found to exhibit a microphase-separated structure with a smaller $d$ value than its linear counterpart. ${ }^{36}$ Furthermore, we and several other groups reported that the miktoarm star architecture is also effective for decreasing the $d$ value, by increasing the branching number while retaining the total molecular weight and $f \cdot{ }^{37-40}$ Thus, the preparation of BCPs with specific chain architectures is a promising way for shrinking the microphase-separated structures without decreasing the $N$ value. Nevertheless, polymers with such architectures require an elaborate synthesis consisting of multiple reaction steps. Therefore, a synthetically more accessible method to reduce the $d$ value through regulating the polymer chain dimensions is of significant interest.

Here, we highlight a crosslinking technique, which involves the intramolecular reaction of a crosslinkable precursor under highly diluted conditions, as a novel approach for reducing the $d$ value of microphase-separated structures. Several reports by 


\section{Synthesis of Crosslinkable Diblock Copolymer}

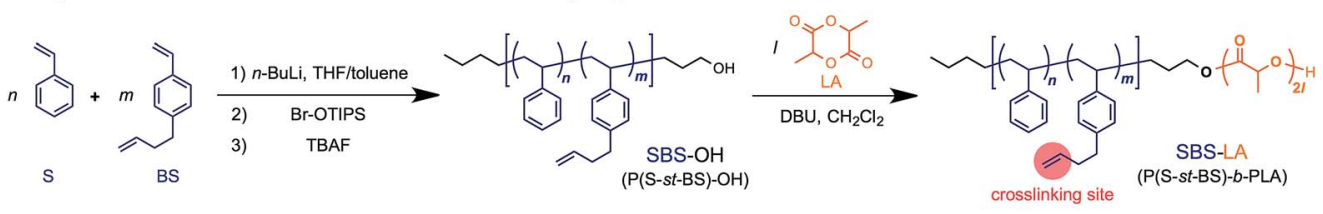

\section{Intramolecular Olefin Metathesis}
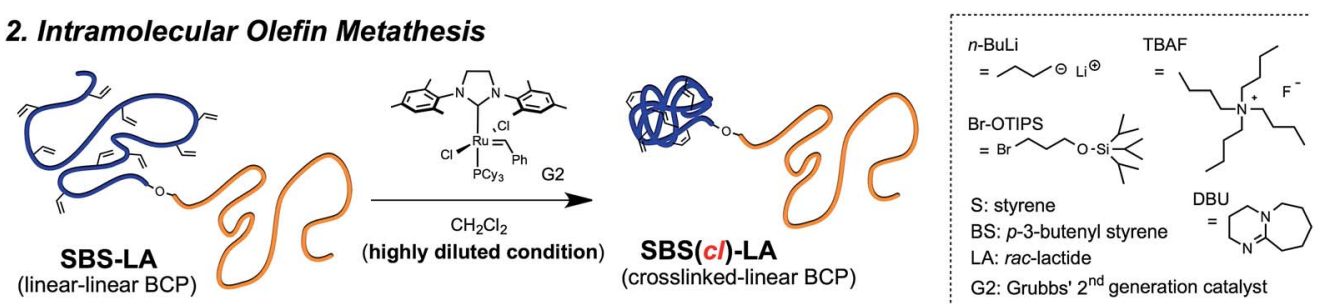

Scheme 1 Synthesis of the crosslinked-linear BCP via the intramolecular olefin metathesis reaction of the linear-linear BCP possessing pendant double bonds as the crosslinking sites.

Meijer et al., ${ }^{41-44}$ Pomposo et al., ${ }^{45-48}$ and Sawamoto et al. ${ }^{49,50}$ clearly demonstrated the remarkable reduction in $R_{\mathrm{g}}$ as well as in the hydrodynamic radius of a single polymer molecule in certain solvents due to the crosslink formation, presenting the potential of this approach for chain compaction even in the bulk. Importantly, intramolecular crosslinking not only is a simple procedure, but also has the capability of controlling the chain dimensions by adjusting the crosslink density. ${ }^{51-54}$ Barner-Kowollik et al. have indeed demonstrated size regulation of intramolecularly crosslinked polymers by varying the content of crosslinkable functionality or the amount of the crosslinking agent. ${ }^{55-58}$ Thus, the intramolecular crosslinking of BCPs would allow fine tuning of the $d$ value as well as modulating the phase structure. However, the microphase separation behavior of the intramolecularly crosslinked BCPs has not been investigated yet.

In the present study, we demonstrate shrinking the microphase-separated structures through restricting the BCP chain dimensions by the intramolecular crosslinking of linear BCPs. Polystyrene- $b$-poly( $r a c$-lactide) (PS- $b$-PLA), which has been widely investigated by Hillmyer et al., ${ }^{59-65}$ was employed as a model system for examining the feasibility of this approach. We designed poly\{[styrene-stat-( $p$-3-butenyl styrene)]-block-(raclactide)\} polymers (P(S-st-BS)-b-PLA or SBS-LA), in which the SBS block can be intramolecularly crosslinked upon the olefin metathesis reaction to produce the crosslinked-linear BCPs, i.e., SBS $(c l)$-LAs (Scheme 1). Indeed, the SBS $(c l)$-LAs exhibited a smaller $d$ value in the microphase-separated structures as compared to the corresponding linear SBS-LA precursors. The minimum $d$ value achieved in this study was $12.0 \mathrm{~nm}$, corresponding to a sub-10 $\mathrm{nm}$ feature size. Furthermore, we succeeded in reducing the domain size up to $22 \%$ by varying the crosslink density of the SBS block.

\section{Results and discussion}

\section{Intramolecular crosslinking of SBS-LAs}

A series of polystyrene- $b$-poly(rac-lactide)s possessing pendant olefin groups on the polystyrene block (SBS-LA, Table 1) were successfully synthesized in two steps according to Scheme 1 . First, the hydroxyl-terminated poly[styrene-st-( $p$-3-butenyl styrene)] (SBS-OH) was prepared via living anionic copolymerization of styrene (S) and p-3-butenyl styrene (BS) in a THF/ toluene co-solvent (Fig. S1, Table S1†), under which the side chain double bond of BS remains intact due to the reduced polarity of the solvent. ${ }^{66}$ This is followed by the termination reaction with Br-OTIPS and the deprotection with tetrabutylammonium fluoride (TBAF). The subsequent ring-opening polymerization of rac-lactide (LA) using the obtained SBS-OH as the macroinitiator yielded the desired SBS-LAs. The total molecular weight $\left(M_{\mathrm{n}, \text { total }}\right)$ and the weight fraction of the SBS block $\left(F_{\mathrm{SBS}}\right)$ were systematically varied to adjust the $d$ values and morphologies of the microphase-separated structures. The mole fraction of BS units in the SBS block $\left(f_{\mathrm{BS}}\right)$ was fixed at around 0.3 or 0.5 (SBS-LAs with $f_{\mathrm{BS}}$ of $c a .0 .5$ have an asterisk in their sample names, i.e., SBS*-LAs.). Note that the $\mathrm{SBS}_{8 \mathrm{k}}$ and $\mathrm{SBS}_{9 \mathrm{k}}^{*}$ blocks were designed to be comparable in degree of polymerization (DP), in order to examine the effect of olefin contents on the chain compaction as well as on the microphase separation behavior.

Recently, our group reported the intramolecular olefin metathesis of linear precursors possessing pendant olefins using Grubbs' $2^{\text {nd }}$ generation catalyst (G2), whose high reactivity and excellent functional group tolerance enabled the crosslinking of a variety of polymers under mild conditions. ${ }^{67,68}$

With a series of SBS-LAs in hand, the intramolecular olefin metathesis was conducted in the presence of G2 to produce the crosslinked-linear diblock copolymers (SBS( $c l$ )-LAs). First, the intramolecular olefin metathesis of $\mathrm{SBS}_{5 \mathrm{k}}-\mathrm{LA}_{7 \mathrm{k}}$ was carried out under highly diluted conditions $\left(\left[\mathrm{SBS}_{5 \mathrm{k}}-\mathrm{LA}_{7 \mathrm{k}}\right]_{0}=0.30 \mathrm{~g} \mathrm{~L}^{-1}\right)$ in $\mathrm{CH}_{2} \mathrm{Cl}_{2}$ at $30^{\circ} \mathrm{C}$ for $3 \mathrm{~h}$ in the presence of $1.0 \mathrm{~mol} \%$ of $\mathrm{G} 2$ with respect to the pendant double bond. The reaction proceeded homogeneously without gelation, giving a soluble product after treatment with ethyl vinyl ether, followed by reprecipitation to remove the catalyst and the preparative SEC purification to isolate the main products from the minor byproducts with high molecular weights. In the ${ }^{1} \mathrm{H}$ NMR spectrum of the product, the intensity of the signals due to the terminal olefin protons ( $e$ and $f$ ) 
Table 1 Molecular characteristics of SBS-LAs

\begin{tabular}{llllrr}
\hline Sample name & $M_{\mathrm{n}, \mathrm{SBS}}\left(\mathrm{DP}, f_{\mathrm{BS}}\right)^{a}$ & $M_{\mathrm{n}, \mathrm{LA}}(\mathrm{DP})^{a}$ & $M_{\mathrm{n}, \text { total }}$ & $F_{\mathrm{SBS}}{ }^{b}$ & $M_{\mathrm{n}, \mathrm{SEC}}{ }^{c}$ \\
\hline $\mathrm{SBS}_{5 \mathrm{k}}-\mathrm{LA}_{7 \mathrm{k}}$ & $4910(40,0.28)$ & $6750(47)$ & 11700 & 0.42 & 13700 \\
SBS $_{8 \mathrm{k}}-\mathrm{LA}_{5 \mathrm{k}}$ & $7940(65,0.31)$ & $4680(32)$ & 12600 & 0.63 & 12500 \\
SBS $_{8 \mathrm{k}}-\mathrm{LA}_{8 \mathrm{k}}$ & $7940(65,0.31)$ & $8250(57)$ & 16200 & 0.49 & 16500 \\
SBS $_{9 \mathrm{k}}^{*}-\mathrm{LA}_{6 \mathrm{k}}$ & $9460(71,0.49)$ & $6420(45)$ & 15900 & 0.60 & 16800 \\
SBS $_{9 \mathrm{k}}^{*} \mathrm{LA}_{11 \mathrm{k}}$ & $9460(71,0.49)$ & $11400(79)$ & 20900 & 0.45 & 1.03 \\
SBS $_{27 \mathrm{k}}-\mathrm{LA}_{13 \mathrm{k}}$ & $27000(224,0.29)$ & $13400(93)$ & 40400 & 0.67 & 300 \\
SBS $_{27 \mathrm{k}}-\mathrm{LA}_{28 \mathrm{k}}$ & $27000(224,0.29)$ & $27900(193)$ & 54900 & 0.49 & 1.03 \\
\end{tabular}

${ }^{a}$ Determined by ${ }^{1} \mathrm{H}$ NMR in $\mathrm{CDCl}_{3} \cdot{ }^{b}$ SBS weight fraction determined using $M_{\mathrm{n}, \mathrm{SBS}}$ and $M_{\mathrm{n}, \mathrm{LA} \cdot} \cdot{ }^{c}$ Determined by SEC in THF using polystyrene standards.

decreased, and those due to the internal olefin protons $(k)$ newly appeared (Fig. 1). The conversion of the terminal olefins (conv.olefin) was calculated to be $93 \%$ by comparing the intensities of $e$ signals before and after the crosslinking, after normalization with the intensity of signals derived from the aromatic protons. Notably, all signals from the SBS block were broadened after the crosslinking reaction although those from the LA block remained unchanged, indicating that only the SBS block was intramolecularly crosslinked without an unwanted reaction on the LA block. The IR spectrum of the product also supported the high olefin conversion ratio. The characteristic absorption band at $1642 \mathrm{~cm}^{-1}$ due to the terminal olefin was no longer observed in the spectrum of the product (Fig. S2 $\dagger$ ). Thus, the ${ }^{1} \mathrm{H}$ NMR and IR studies confirmed the crosslink formation via the olefin metathesis reaction.

To further verify the intramolecular crosslink formation, SEC measurement was performed on $\mathrm{SBS}_{5 \mathrm{k}}-\mathrm{LA}_{7 \mathrm{k}}$ and its reaction product. As can be seen in Fig. 2(a), the SEC trace of the crosslinked product exhibited a monomodal peak in the lower molecular weight region as compared to that of $\mathrm{SBS}_{5 \mathrm{k}}-\mathrm{LA}_{7 \mathrm{k}}$, implying a decrease in the hydrodynamic volume through the crosslinking reaction (the SEC trace of the product obtained before preparative SEC purification is shown in Fig. S3 $\dagger$ ). Under the assumption that the LA block maintains its linear structure

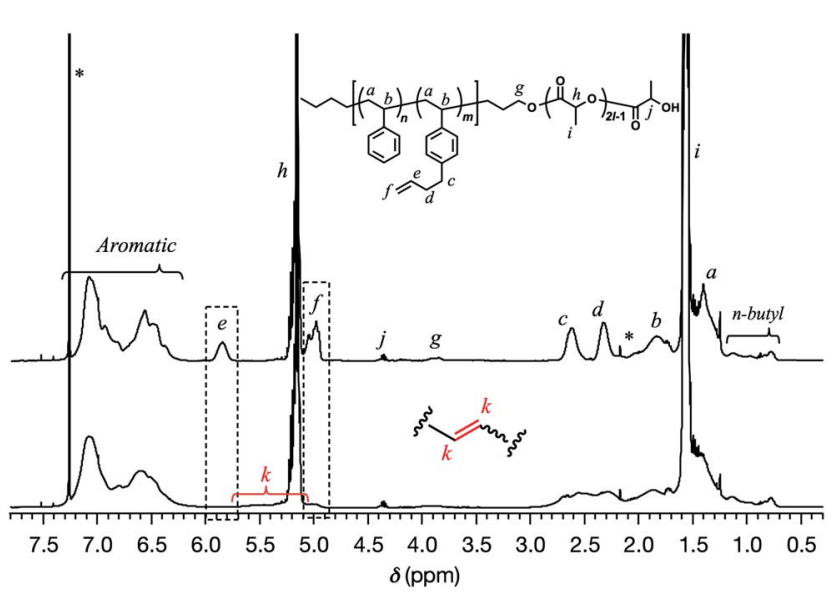

Fig. $1{ }^{1} \mathrm{H} N M R$ spectra of $\mathrm{SBS}_{5 \mathrm{k}}-\mathrm{LA}_{7 \mathrm{k}}$ (upper) and $\mathrm{SBS}_{5 \mathrm{k}}(\mathrm{Cl})-\mathrm{LA}_{7 \mathrm{k}}$ (lower) in $\mathrm{CDCl}_{3}(400 \mathrm{MHz})$. after intramolecular crosslinking, we can define the shrinking factor of the SBS block, $\langle G\rangle_{\text {SBS }}$, using the following equations:

$$
\begin{gathered}
\langle G\rangle_{\mathrm{SBS}}=\frac{M_{\mathrm{p}, \mathrm{SEC}}[\mathrm{SBS}(c l)-\mathrm{LA}]-M_{\mathrm{p}, \mathrm{SEC}}[\mathrm{LA}]}{M_{\mathrm{p}, \mathrm{SEC}}[\mathrm{SBS}-\mathrm{OH}]} \\
M_{\mathrm{p}, \mathrm{SEC}}[\mathrm{LA}]=M_{\mathrm{p}, \mathrm{SEC}}[\mathrm{SBS}-\mathrm{LA}]-M_{\mathrm{p}, \mathrm{SEC}}[\mathrm{SBS}-\mathrm{OH}]
\end{gathered}
$$

where $M_{\mathrm{p}, \mathrm{SEC}}[\mathrm{SBS}(c l)-\mathrm{LA}], M_{\mathrm{p}, \mathrm{SEC}}[\mathrm{SBS}-\mathrm{OH}]$, and $M_{\mathrm{p}, \mathrm{SEC}}[\mathrm{SBS}-\mathrm{LA}]$ stand for the molecular weights calculated from the peak top of the corresponding SEC traces. The $\langle G\rangle_{\text {SBS }}$ value in Fig. 2(a) was

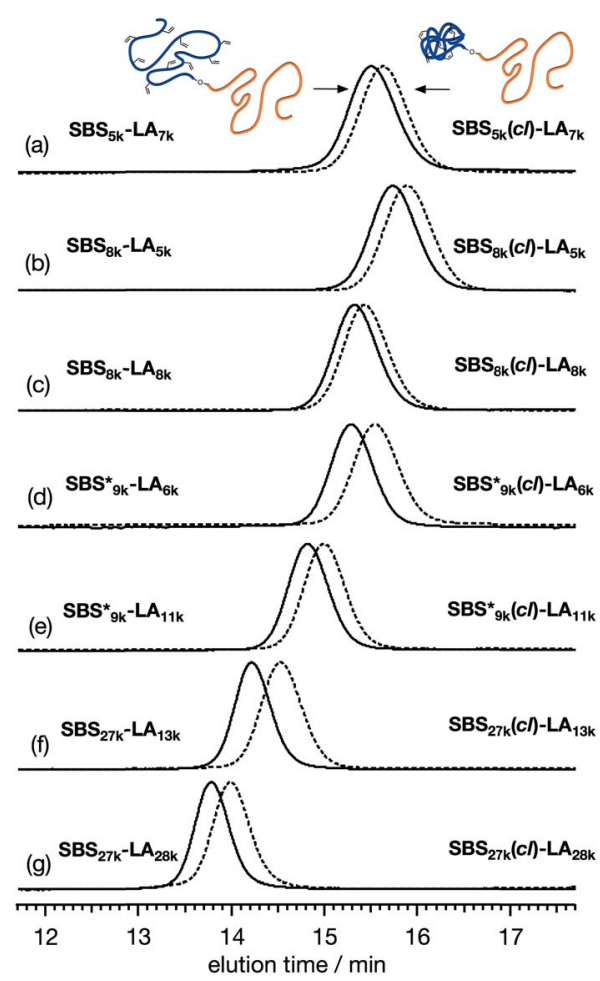

Fig. 2 SEC traces of (a) $\mathrm{SBS}_{5 \mathrm{k}}-\mathrm{LA}_{7 \mathrm{k}}$ and $\mathrm{SBS}_{5 \mathrm{k}}(\mathrm{cl})-\mathrm{LA}_{7 \mathrm{k}}$, (b) $\mathrm{SBS}_{8 \mathrm{k}}-\mathrm{LA}_{5 \mathrm{k}}$ and $\mathrm{SBS}_{8 \mathrm{k}}(\mathrm{Cl})-\mathrm{LA}_{5 \mathrm{k}}$, (c) $\mathrm{SBS}_{8 \mathrm{k}}-\mathrm{LA}_{8 \mathrm{k}}$ and $\mathrm{SBS}_{8 \mathrm{k}}(\mathrm{Cl})-\mathrm{LA}_{8 \mathrm{k}}$, (d) $\mathrm{SBS}_{9 \mathrm{k}}^{*}-\mathrm{LA}_{6 \mathrm{k}}$ and $\mathrm{SBS}_{9 \mathrm{k}}^{*}(c l)-\mathrm{LA}_{6 \mathrm{k}}$, (e) $\mathrm{SBS}_{9 \mathrm{k}}^{*}-\mathrm{LA}_{11 \mathrm{k}}$ and $\mathrm{SBS}_{9 \mathrm{k}}^{*}(c l)-\mathrm{LA}_{11 \mathrm{k}}$, (f) $\mathrm{SBS}_{27 \mathrm{k}}-$ $\mathrm{LA}_{13 \mathrm{k}}$ and $\mathrm{SBS}_{27 \mathrm{k}}(\mathrm{Cl})-\mathrm{LA}_{13 \mathrm{k}}$, and $(\mathrm{g}) \mathrm{SBS}_{27 \mathrm{k}}-\mathrm{LA}_{28 \mathrm{k}}$ and $\mathrm{SBS}_{27 \mathrm{k}}(\mathrm{Cl})-\mathrm{LA}_{28 \mathrm{k}}$ (eluent, THF; flow rate, $1.0 \mathrm{~mL} \mathrm{~min}^{-1}$ ). SBS-LAs and the corresponding SBS $(C l)$-LAs are presented using solid and dashed lines, respectively. 
0.78 , which was comparable to the $\langle G\rangle$ value $(0.79)$ obtained from the intramolecular crosslinking of $\mathrm{SBS}_{5 \mathrm{k}}-\mathrm{OH}$ (Table S1 $\dagger$ ). Based on the ${ }^{1} \mathrm{H}$ NMR, IR, and SEC analyses, we concluded that the crosslinked-linear diblock copolymer, i.e., $\mathrm{SBS}_{5 \mathrm{k}}(\mathrm{cl})-\mathrm{LA}_{7 \mathrm{k}}$, was successfully obtained. In a similar manner, SBS-LAs with different compositions and molecular weights were also successfully converted to the corresponding SBS $(c l)$-LAs with sufficient conv. olefin values (Table 2, Fig. 2(b)-(g), and S3-S15†). It is worth noting that the $\langle G\rangle_{\mathrm{SBS}}$ values for $\operatorname{SBS}_{9 \mathrm{k}}^{*}(c l)-\mathrm{LA}_{6 \mathrm{k}}$ and $\mathrm{SBS}_{9 \mathrm{k}}^{*}(c l)-\mathrm{LA}_{11 \mathrm{k}}(0.67$ and 0.66$)$ were apparently lower than those of $\operatorname{SBS}_{8 \mathrm{k}}(c l)-\mathrm{LA}_{5 \mathrm{k}}$ and $\operatorname{SBS}_{8 \mathrm{k}}(c l)-\mathrm{LA}_{8 \mathrm{k}}(0.81$ and 0.84$)$ despite the comparable DP values of the SBS block, indicating that a higher crosslinking density led to further reduction in the chain dimensions.

\section{Thermal properties}

Since the intramolecularly crosslinked polymers obviously differ in molecular mobility from typical polymers with random coils, their bulk thermal property is an important consideration when evaluating the microphase separation behavior. Thus, the obtained SBS-LAs, SBS $(c l)$-LAs, and the corresponding homopolymers (SBS-OHs, SBS( $c l$ )-OHs, and PLA) were characterized by differential scanning calorimetry (DSC) to determine their glass transition temperature $\left(T_{\mathrm{g}}\right)$ (Tables 2 and $\mathrm{S} 1 \dagger$ ). The DSC curves of SBS-LAs and SBS $(c l)$-LAs during the second heating process are shown in Fig. S16. $\dagger$ See also Fig. S17† for the DSC curves of SBS-OHs, SBS $(c l)-\mathrm{OHs}$, and PLA.

For $\mathrm{SBS}_{5 \mathrm{k}}-\mathrm{LA}_{7 \mathrm{k}}$ and $\mathrm{SBS}_{5 \mathrm{k}}(c l)-\mathrm{LA}_{7 \mathrm{k}}$, two sets of baseline shifts due to the separate glass transitions of SBS and LA blocks were observed, indicating the formation of microphase-separated structures (Fig. 3). Importantly, the $T_{\mathrm{g}}$ of the $\operatorname{SBS}_{5 \mathrm{k}}(c l)$ block was determined to be $91{ }^{\circ} \mathrm{C}$, which was much higher than that of the $\mathrm{SBS}_{5 \mathrm{k}}$ block, i.e., $59{ }^{\circ} \mathrm{C}$, while there was no significant difference in $T_{\mathrm{g}}$ for the LA blocks between $\mathrm{SBS}_{5 \mathrm{k}}-\mathrm{LA}_{7 \mathrm{k}}\left(51^{\circ} \mathrm{C}\right)$ and $\mathrm{SBS}_{5 \mathrm{k}}(\mathrm{cl})-\mathrm{LA}_{7 \mathrm{k}}\left(54^{\circ} \mathrm{C}\right)$. The increased $T_{\mathrm{g}}$ of the crosslinked
SBS block compared to its linear counterparts strongly reflected a decrease in the segmental chain mobility, which again confirmed the formation of the intramolecularly crosslinked structure. A similar thermal behavior was observed for all other SBS $(c l)$-LAs (Fig. S16 $\dagger$ ). It should also be noted that the determined $T_{\mathrm{g}}$ values of SBS-LAs and $\operatorname{SBS}(c l)$-LAs were comparable with those of the corresponding homopolymers (Fig. S17 and Table $\left.\mathrm{S}^{\dagger} \dagger\right)$. We could not detect the baseline shift of the $\mathrm{SBS}_{9 \mathrm{k}}^{*}$ block in $\mathrm{SBS}_{9 \mathrm{k}}^{*}-\mathrm{LA}_{6 \mathrm{k}}$ and $\mathrm{SBS}_{9 \mathrm{k}}^{*}-\mathrm{LA}_{11 \mathrm{k}}$ (Fig. S16(d) and (e) $\dagger$ ). Considering that the $T_{\mathrm{g}}$ value of $\mathrm{SBS}_{9 \mathrm{k}}^{*}-\mathrm{OH}$ was $46{ }^{\circ} \mathrm{C}$ (Table $\mathrm{S} 1 \dagger)$, the baseline shift due to the $\mathrm{SBS}_{9 \mathrm{k}}^{*}$ block seems to overlap with that of the LA blocks at around $50{ }^{\circ} \mathrm{C}$. Surprisingly, the $T_{\mathrm{g}}$ values of the $\operatorname{SBS}_{9 \mathrm{k}}^{*}(c l)$ block $\left(138{ }^{\circ} \mathrm{C}\right.$ for $\operatorname{SBS}_{9 \mathrm{k}}^{*}(c l)-\mathrm{LA}_{6 \mathrm{k}}$ and $143{ }^{\circ} \mathrm{C}$ for $\left.\operatorname{SBS}_{9 \mathrm{k}}^{*}(c l)-\mathrm{LA}_{11 \mathrm{k}}\right)$ were considerably higher than that of the corresponding linear $\mathrm{SBS}_{9 \mathrm{k}}^{*}$ block (around $50{ }^{\circ} \mathrm{C}$ ). To our knowledge, such a dramatic increase in the $T_{\mathrm{g}}$ values has not been reported for intramolecularly crosslinked polymers to date. ${ }^{68-73}$ This is probably due to the substantial incorporation of the crosslinkable units into the precursor (50 $\mathrm{mol} \%$ ) and the high conversion ratio to the crosslinkages (conv. ${ }_{\text {olefin }}=c a$. $90 \%)$. The $T_{\mathrm{g}}$ values of $\mathrm{SBS}_{27 \mathrm{k}}(c l)$ blocks in $\mathrm{SBS}_{27 \mathrm{k}}(c l)-\mathrm{LA}_{10 \mathrm{k}}$ $\left(140^{\circ} \mathrm{C}\right)$ and $\operatorname{SBS}_{27 \mathrm{k}}(c l)-\mathrm{LA}_{28 \mathrm{k}}\left(137^{\circ} \mathrm{C}\right)$ were also very high, which is surely due to their high molecular weights.

\section{Microphase separation behavior in the bulk state}

To investigate the microphase-separated structures of SBS-LAs and SBS $(c l)$-LAs, a small-angle X-ray scattering (SAXS) study was carried out on their bulk samples. Prior to the SAXS experiments, the samples were thermally annealed for $1 \mathrm{~h}$ under vacuum at temperatures higher than their measured $T_{\mathrm{g}}$ values. The resulting morphological characteristics of all samples are summarized in Table 3 . The SAXS profile of $\mathrm{SBS}_{8 \mathrm{k}}-\mathrm{LA}_{8 \mathrm{k}}\left(F_{\mathrm{SBS}}=0.49\right)$ showed a primary scattering peak at $q^{*}=0.413 \mathrm{~nm}^{-1}$ with higher-ordered scattering peaks at $2 q^{*}, 3 q^{*}$, and $4 q^{*}$ positions, indicative of a well-ordered lamellar (LAM) morphology (Fig. 4(a), upper). The

Table 2 Characterization data for SBS-LAs and SBS(Cl)-LAs

\begin{tabular}{|c|c|c|c|c|c|c|}
\hline Sample name & Conv. $_{\text {olefin }}{ }^{a}(\%)$ & $M_{\mathrm{p}, \mathrm{SEC}}{ }^{b}$ & $\nexists^{b}$ & $\langle G\rangle_{\mathrm{SBS}^{c}}$ & $T_{\mathrm{g}, \mathrm{SBS}}{ }^{d}\left({ }^{\circ} \mathrm{C}\right)$ & $T_{\mathrm{g}, \mathrm{LA}}{ }^{d}\left({ }^{\circ} \mathrm{C}\right)$ \\
\hline $\mathrm{SBS}_{5 \mathrm{k}}-\mathrm{LA}_{7 \mathrm{k}}$ & & 13400 & 1.03 & & 59 & 51 \\
\hline $\operatorname{SBS}_{5 \mathrm{k}}(c l)-\mathrm{LA}_{7 \mathrm{k}}$ & 93 & 12200 & 1.03 & 0.78 & 91 & 54 \\
\hline $\operatorname{SBS}_{8 \mathrm{k}}(c l)-\mathrm{LA}_{5 \mathrm{k}}$ & 88 & 11100 & 1.03 & 0.81 & 109 & 54 \\
\hline $\mathrm{SBS}_{8 \mathrm{k}}-\mathrm{LA}_{8 \mathrm{k}}$ & & 16500 & 1.03 & & 63 & 52 \\
\hline $\operatorname{SBS}_{8 \mathrm{k}}(c l)-\mathrm{LA}_{8 \mathrm{k}}$ & 79 & 15300 & 1.03 & 0.84 & 110 & 55 \\
\hline $\mathrm{SBS}_{9 \mathrm{k}}^{*}-\mathrm{LA}_{11 \mathrm{k}}$ & & 23600 & 1.03 & & - & 51 \\
\hline $\operatorname{SBS}_{9 \mathrm{k}}^{*}(c l)-\mathrm{LA}_{11 \mathrm{k}}$ & 89 & 20700 & 1.03 & 0.66 & 143 & 55 \\
\hline $\mathrm{SBS}_{27 \mathrm{k}}-\mathrm{LA}_{13 \mathrm{k}}$ & & 39300 & 1.03 & & 76 & 52 \\
\hline $\operatorname{SBS}_{27 \mathrm{k}}(c l)-\mathrm{LA}_{13 \mathrm{k}}$ & 88 & 28200 & 1.03 & 0.45 & 140 & 53 \\
\hline $\mathrm{SBS}_{27 \mathrm{k}}-\mathrm{LA}_{28 \mathrm{k}}$ & & 54400 & 1.03 & & 80 & 55 \\
\hline
\end{tabular}

${ }^{a}$ Determined by ${ }^{1} \mathrm{H}$ NMR in $\mathrm{CDCl}_{3} .{ }^{b}$ Determined by SEC in THF using polystyrene standards. ${ }^{c}$ Calculated using eqn (1) and (2). $M_{\mathrm{p}, \mathrm{SEC}}\left[\mathrm{SBS} \mathrm{K}_{5 \mathrm{k}}-\mathrm{OH}\right]$ $=5360, M_{\mathrm{p}, \mathrm{SEC}}\left[\mathrm{SBS}_{8 \mathrm{k}}-\mathrm{OH}\right]=7290, M_{\mathrm{p}, \mathrm{SEC}}\left[\mathrm{SBS}_{9 \mathrm{k}}^{*}-\mathrm{OH}\right]=8510, M_{\mathrm{p}, \mathrm{SEC}}\left[\mathrm{SBS}_{19 \mathrm{k}}-\mathrm{OH}\right]=20100 .^{d}$ Determined by DSC at the heating rate of $10{ }^{\circ} \mathrm{C}$ min ${ }^{-1}$. 


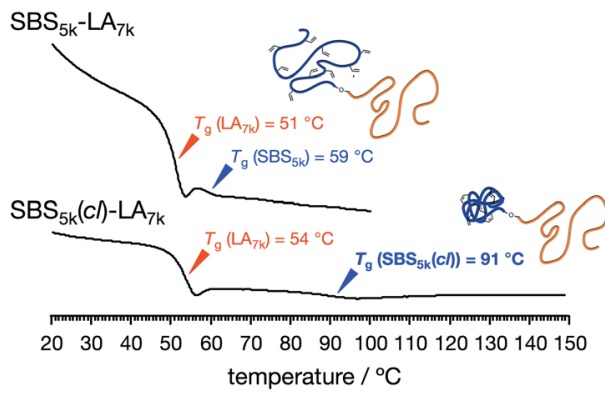

Fig. 3 DSC curves during the $2^{\text {nd }}$ heating process of $\mathrm{SBS}_{5 \mathrm{k}}-\mathrm{LA}_{7 \mathrm{k}}$ (upper) and $\mathrm{SBS}_{5 \mathrm{k}}(\mathrm{Cl})-\mathrm{LA}_{7 \mathrm{k}}$ (lower)

$d$ value of the LAM structure was determined to be $15.2 \mathrm{~nm}$ based on the relationship of $d=2 \pi / q^{*}$. The SAXS profile of $\operatorname{SBS}_{8 \mathrm{k}}(\mathrm{cl})-$ $\mathrm{LA}_{8 \mathrm{k}}$ also exhibited scattering peaks $\left(q^{*}=0.469 \mathrm{~nm}^{-1}, 2 q^{*}\right.$, and $\left.3 q^{*}\right)$ corresponding to the LAM morphology with a $d$ value of $13.4 \mathrm{~nm}$ (Fig. 4(a), lower). Importantly, these results clearly demonstrated a decrease in the $d$ value by $12 \%$ after the intramolecular crosslinking process, indicating the compact chain dimensions of the resultant polymers in the bulk state. Because the chain dimensions of the LA block are presumed to be almost unchanged even after the intramolecular crosslinking process, the decrease in $d$ should be attributed to a reduction in the chain volume of the SBS block. Transmission electron microscopy (TEM) observation of the microtomed samples was performed to further confirm the above hypothesis. TEM images of $\mathrm{SBS}_{8 \mathrm{k}}-\mathrm{LA}_{8 \mathrm{k}}$ and $\operatorname{SBS}_{8 \mathrm{k}}(c l)-\mathrm{LA}_{8 \mathrm{k}}$ exhibited the line patterns corresponding to the LAM morphology without any staining, in which the dark and bright parts were assigned to the SBS (SBS $(c l))$ block and the LA block, respectively (Fig. 4(b) and (c)). The large wrinkles in the horizontal direction are defects that occurred during ultramicrotome cutting. The estimated $d$ value of $15.5-16.0 \mathrm{~nm}$ for $\mathrm{SBS}_{8 \mathrm{k}}-\mathrm{LA}_{8 \mathrm{k}}$ is in good agreement with that determined from the SAXS profile $(d=15.2 \mathrm{~nm})$. In the case of $\mathrm{SBS}_{8 \mathrm{k}}(c l)-\mathrm{LA}_{8 \mathrm{k}}$, the $d$ value was estimated to be $14.0-14.5 \mathrm{~nm}$ from the TEM image, which is slightly different from the SAXS result $(d=13.4 \mathrm{~nm})$. Nevertheless, the LAM period of $\mathrm{SBS}_{8 \mathrm{k}}(c l)-\mathrm{LA}_{8 \mathrm{k}}$ was found to be smaller than that of $\mathrm{SBS}_{8 \mathrm{k}}-\mathrm{LA}_{8 \mathrm{k}}$, according to both the real space TEM image and the SAXS results in the reciprocal space.
$\mathrm{SBS}_{5 \mathrm{k}}-\mathrm{LA}_{7 \mathrm{k}}\left(F_{\mathrm{SBS}}=0.42\right), \mathrm{SBS}_{9 \mathrm{k}}^{*}(c l)-\mathrm{LA}_{11 \mathrm{k}}\left(F_{\mathrm{SBS}}=0.45\right)$, and the corresponding SBS $(c l)$-LAs also exhibited the LAM morphology, as expected from their $F_{\mathrm{SBS}}$ values (Fig. 5(a) and (b)). From the SAXS results of the polymers with the lowest molecular weights $\left(\mathrm{SBS}_{5 \mathrm{k}}-\mathrm{LA}_{7 \mathrm{k}}\right.$ and $\left.\mathrm{SBS}_{5 \mathrm{k}}(c l)-\mathrm{LA}_{7 \mathrm{k}}\right)$, the $d$ value was reduced from 13.4 to $12.0 \mathrm{~nm}$ after intramolecular crosslinking. These $d$ values equal to sub-10 $\mathrm{nm}$ half-pitch, demonstrating that the presented approach can be applied at such small size scales. Remarkably, $\operatorname{SBS}_{9 \mathrm{k}}^{*}(c l)-\mathrm{LA}_{11 \mathrm{k}}$ exhibited the maximum downsizing in $d$ in this work, being $22 \%$ smaller compared to the corresponding linear $\mathrm{SBS}_{9 \mathrm{k}}^{*}-\mathrm{LA}_{11 \mathrm{k}}(d=15.5$ vs. $19.8 \mathrm{~nm})$. As described above, the $\mathrm{SBS}_{8 \mathrm{k}}$ and $\mathrm{SBS}_{9 \mathrm{k}}^{*}$ blocks were designed to be different in $f_{\mathrm{BS}}$ but with the comparable DP values, which enabled us to examine the effect of olefin contents on the size of the microphase-separated structures. As expected, the decrease ratio in $d$ is greater for $\mathrm{SBS}_{9 \mathrm{k}}^{*}(c l)-\mathrm{LA}_{11 \mathrm{k}}$ than for $\mathrm{SBS}_{8 \mathrm{k}}(c l)-\mathrm{LA}_{8 \mathrm{k}}(22 \% v s$. $12 \%$ ), in spite of their comparable DPs in the crosslinkable SBS block. This result clearly demonstrates that increasing the crosslinking density of BCP is an effective approach to further reducing the feature sizes of the microphase-separated structures.

Notably, the even-ordered peaks in the SAXS profiles of $\mathrm{SBS}_{5 \mathrm{k}^{-}}$ $\mathrm{LA}_{7 \mathrm{k}}$ and $\mathrm{SBS}_{9 \mathrm{k}}^{*}-\mathrm{LA}_{11 \mathrm{k}}$ were absent (or suppressed) (Fig. 5(a) and (b), upper), indicating that the two phases of the LAM morphology were highly symmetric. ${ }^{74}$ On the other hand, the SAXS profiles of intramolecularly crosslinked products, i.e., $\operatorname{SBS}_{5 \mathrm{k}}(c l)-\mathrm{LA}_{7 \mathrm{k}}$ and $\mathrm{SBS}_{9 \mathrm{k}}^{*}(c l)-\mathrm{LA}_{11 \mathrm{k}}$, clearly exhibited a scattering peak at the $2 q^{*}$ position with an intensity similar to those at the $3 q^{*}$ position (Fig. $5(\mathrm{a})$ and (b), lower), indicative of the transition from the symmetric LAM to an asymmetric one (Fig. 5(c)). These results support our assumption that the major reason for the decrease in $d$ is reduction of feature sizes of the SBS phase.

The SAXS profile of $\mathrm{SBS}_{8 \mathrm{k}}-\mathrm{LA}_{5 \mathrm{k}}\left(F_{\mathrm{SBS}}=0.63\right)$ showed a primary scattering peak at $q^{*}=0.500 \mathrm{~nm}^{-1}$ and higher-ordered ones at $\sqrt{3} q^{*}, 2 q^{*}, \sqrt{7} q^{*}$, and $3 q^{*}$ positions, which correspond to the hexagonally close-packed cylinder (HEX) morphology with $d=$ $12.6 \mathrm{~nm}$ (Fig. 6(a), upper). For the HEX, the $d$ value was converted to the center-to-center distance between cylinders $\left(d_{\mathrm{C}-\mathrm{C}}=2 d / \sqrt{3}\right)$ to be $14.5 \mathrm{~nm}$. The SAXS profile of $\mathrm{SBS}_{8 \mathrm{k}}(c l)-\mathrm{LA}_{5 \mathrm{k}}$ also suggested the HEX morphology with $d_{\mathrm{C}-\mathrm{C}}=12.9 \mathrm{~nm}$, as revealed by the scattering peaks observed at $q^{*}\left(0.563 \mathrm{~nm}^{-1}\right), 2 q^{*}$, and $\sqrt{7} q^{*}$ (Fig. 6(a), lower), representing an $11 \%$ decrease in the

Table 3 Morphological characteristics of SBS-LAs and SBS(Cl)-LAs in the bulk

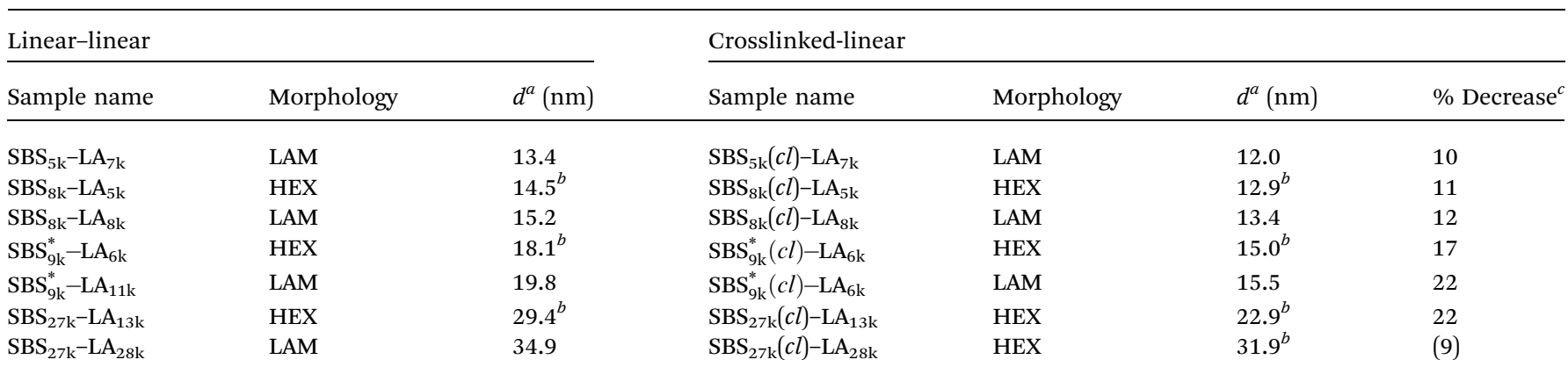

${ }^{a}$ Determined by SAXS. ${ }^{b} d$ value was converted to the center-to-center distance between cylinders $\left(d_{\mathrm{C}-\mathrm{C}}\right) .{ }^{c}$ Decreasing ratio of the $d\left(d_{\mathrm{C}-\mathrm{C}}\right)$ value. 


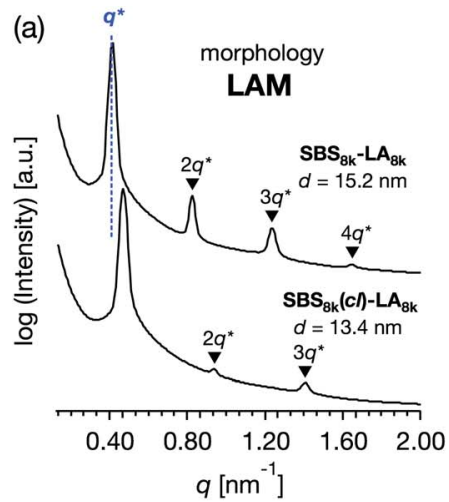

(b) $\mathrm{SBS}_{8 \mathrm{k}}-\mathrm{LA}_{8 \mathrm{k}}$

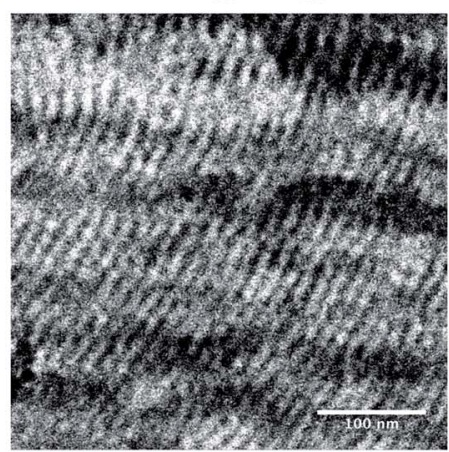

(c) $\quad \mathrm{SBS}_{8 \mathrm{k}}(c)-\mathrm{LA}_{8 \mathrm{k}}$

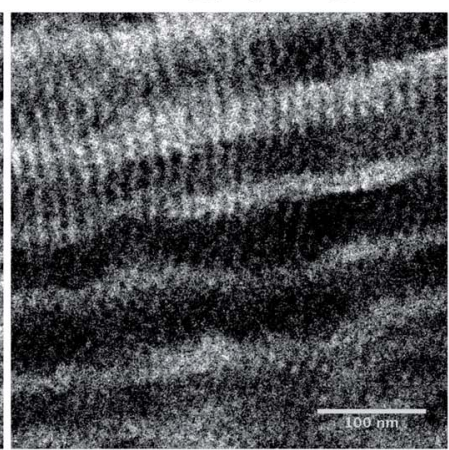

Fig. 4 (a) SAXS profiles of $\mathrm{SBS}_{8 \mathrm{k}}-\mathrm{LA}_{8 \mathrm{k}}$ (upper) and $\mathrm{SBS}_{8 \mathrm{k}}(\mathrm{Cl})-\mathrm{LA} \mathrm{A}_{8 \mathrm{k}}$ (lower). Cross-sectional TEM images of (b) $\mathrm{SBS}_{8 \mathrm{k}}-\mathrm{LA}_{8 \mathrm{k}}$ and (c) $\mathrm{SBS} \mathrm{Sk}_{8 \mathrm{k}}(\mathrm{Cl})-\mathrm{LA} \mathrm{A}_{8 \mathrm{k}}$. The scale bar is $100 \mathrm{~nm}$.

$d_{\mathrm{C}-\mathrm{C}}$ value compared with the corresponding linear $\mathrm{SBS}_{8 \mathrm{k}}-\mathrm{LA}_{5 \mathrm{k}}$. Since the HEX-forming SBS-LAs were designed to have longer SBS blocks (matrix) and shorter LA blocks (cylinder domain), the structure transition model in Fig. 6(b) is assumed. In this model, the volume of the SBS matrix is reduced after intramolecular crosslinking to decrease the $d_{\mathrm{C}-\mathrm{C}}$ while the LA cylinder diameter is maintained. Thus, we successfully reduced the feature size in both the LAM and HEX morphologies.

$\mathrm{SBS}_{9 \mathrm{k}}^{*}-\mathrm{LA}_{6 \mathrm{k}}\left(F_{\mathrm{SBS}}=0.60\right), \mathrm{SBS}_{19 \mathrm{k}}-\mathrm{LA}_{10 \mathrm{k}}\left(F_{\mathrm{SBS}}=0.65\right)$, and the corresponding SBS $(c l)$-LAs also exhibited the HEX morphology as expected from their $F_{\mathrm{SBS}}$ values. A similar result was obtained for the case of $\mathrm{SBS}_{9 \mathrm{k}}^{*}-\mathrm{LA}_{6 \mathrm{k}}$, and
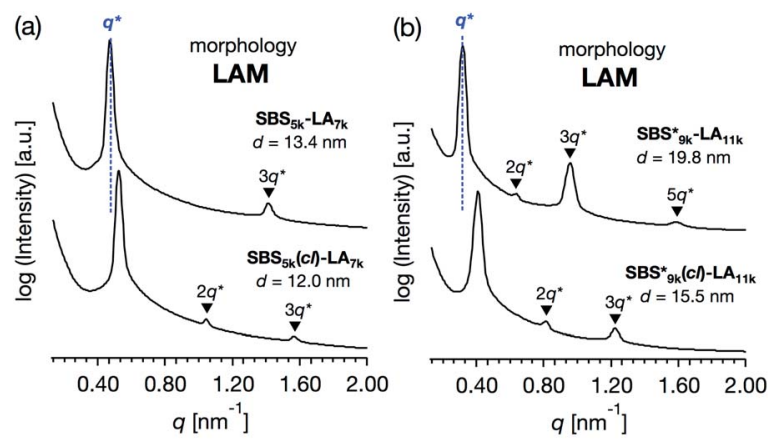

(c)

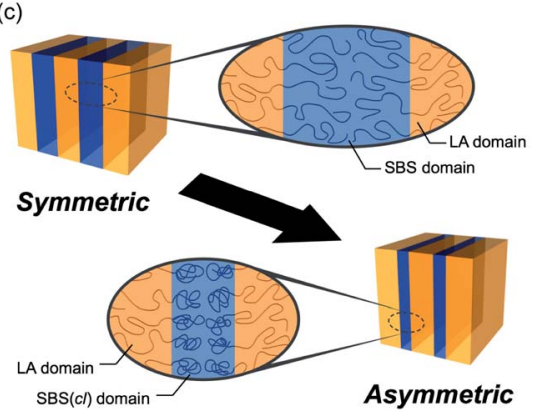

Fig. 5 SAXS profiles for the bulk samples of (a) $\mathrm{SBS}_{5 \mathrm{k}}-\mathrm{LA}_{7 \mathrm{k}}$ and $\mathrm{SBS}_{5 \mathrm{k}}(\mathrm{Cl})-\mathrm{LA}_{7 \mathrm{k}}$ annealed at $150{ }^{\circ} \mathrm{C}$ and (b) $\mathrm{SBS}_{9 \mathrm{k}}^{*}-\mathrm{LA}_{11 \mathrm{k}}$ and $\mathrm{SBS}_{9 \mathrm{k}}^{*}(c l)-\mathrm{LA}_{11 \mathrm{k}}$ annealed at $180{ }^{\circ} \mathrm{C}$. (c) Schematic illustration of the structural transition in LAM morphology via the intramolecular crosslinking. SBS domains and LA domains are shown in blue and yellow, respectively.
$\mathrm{SBS}_{9 \mathrm{k}}^{*}-\mathrm{LA}_{11 \mathrm{k}}: \mathrm{SBS}_{9 \mathrm{k}}^{*}(c l)-\mathrm{LA}_{6 \mathrm{k}}$ has a $d_{\mathrm{C}-\mathrm{C}}$ value $17 \%$ smaller $(15.0$ $\mathrm{nm})$ compared to the linear $\mathrm{SBS}_{9 \mathrm{k}}^{*}-\mathrm{LA}_{6 \mathrm{k}}(18.1 \mathrm{~nm}$, Fig. 6(c)), representing a larger decrease ratio than that for $\operatorname{SBS}_{8 \mathrm{k}}(c l)-\mathrm{LA}_{5 \mathrm{k}}$ (11\%, Fig. 6(a)) because of the higher crosslink density. In the case of the high-molecular-weight $\mathrm{SBS}_{27 \mathrm{k}}-\mathrm{LA}_{13 \mathrm{k}}$, a larger volume reduction of the SBS block is expected after the crosslinking reaction as indicated by the $\langle G\rangle_{\mathrm{SBS}}$ values. Indeed, $\mathrm{SBS}_{27 \mathrm{k}}(c l)-\mathrm{LA}_{13 \mathrm{k}}$ exhibited a $22 \%$ reduction in $d_{\mathrm{C}-\mathrm{C}}(22.9 \mathrm{~nm})$ compared to that of the corresponding linear $\mathrm{SBS}_{27 \mathrm{k}}-\mathrm{LA}_{13 \mathrm{k}}$ (29.4 nm, Fig. 6(d)).
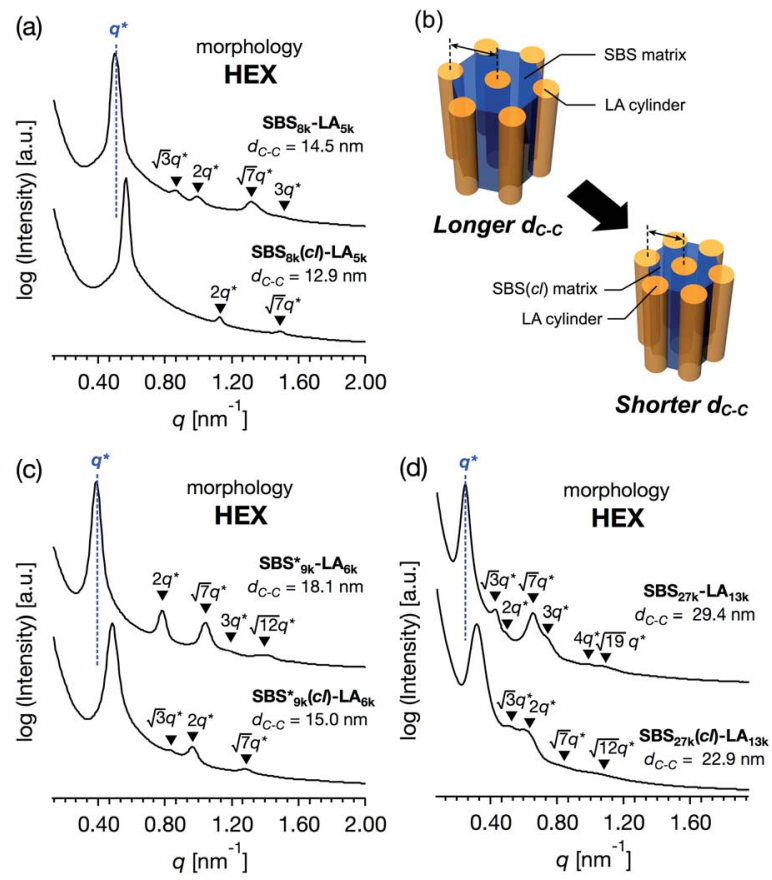

Fig. 6 SAXS profiles for the bulk samples of (a) $\mathrm{SBS}_{8 \mathrm{k}}-\mathrm{LA}_{5 \mathrm{k}}$ and $\mathrm{SBS}_{8 \mathrm{k}}(\mathrm{Cl})-\mathrm{LA}_{5 \mathrm{k}}$ annealed at $150{ }^{\circ} \mathrm{C}$, (c) $\mathrm{SBS}_{9 \mathrm{k}}^{*}-\mathrm{LA}_{6 \mathrm{k}}$ and $\mathrm{SBS}_{9 \mathrm{k}}^{*}(c l)-\mathrm{LA}_{6 \mathrm{k}}$ annealed at $180^{\circ} \mathrm{C}$ and (d) $\mathrm{SBS}_{27 \mathrm{k}}-\mathrm{LA}_{13 \mathrm{k}}$ and $\mathrm{SBS}_{27 \mathrm{k}}(\mathrm{Cl})-\mathrm{LA}_{13 \mathrm{k}}$ annealed at $180{ }^{\circ} \mathrm{C}$. (b) Schematic illustration of the structural transition in HEX morphology via the intramolecular cross-linking. SBS domains and LA domains are shown in blue and yellow, respectively. 


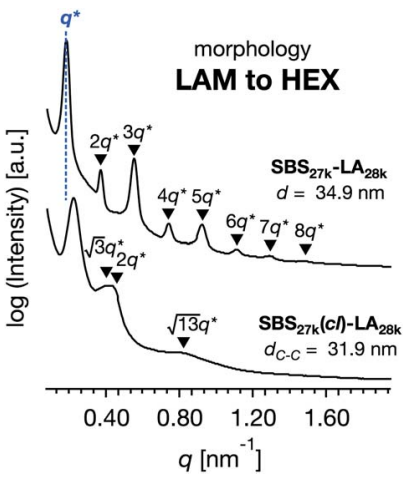

Fig. 7 SAXS profiles for the bulk samples of $\mathrm{SBS}_{27 \mathrm{k}}-\mathrm{LA}_{28 \mathrm{k}}$ and $\mathrm{SBS}_{27 \mathrm{k}}(\mathrm{Cl})-\mathrm{LA}_{28 \mathrm{k}}$ annealed at $180^{\circ} \mathrm{C}$.

While $\mathrm{SBS}_{27 \mathrm{k}}-\mathrm{LA}_{28 \mathrm{k}}\left(F_{\mathrm{SBS}}=0.49\right)$ exhibited a well-ordered LAM morphology, the SAXS profile of $\mathrm{SBS}_{27 \mathrm{k}}(\mathrm{cl})-\mathrm{LA}_{28 \mathrm{k}}$ showed scattering peaks $\left(q^{*}, \sqrt{3} q^{*}, 2 q^{*}\right.$, and $\left.\sqrt{13} q^{*}\right)$ corresponding to the HEX morphology (Fig. 7). Such a change in phase was only observed in this BCP with the highest molecular weight, and it should also be attributed to a significant change in the effective volume fraction of the SBS block due to the intramolecular crosslinking. Therefore, the presented methodology can be applied for not only downsizing the feature but also varying the morphology in the microphase-separated structures.

\section{Microphase separation behavior in the thin film state}

For the lithographic application, microphase separation in the thin film state is of particular importance. We therefore finally investigated the thin film morphologies of the HEX-forming $\mathrm{SBS}_{27 \mathrm{k}}-\mathrm{LA}_{13 \mathrm{k}}$ and $\mathrm{SBS}_{27 \mathrm{k}}(\mathrm{cl})-\mathrm{LA}_{13 \mathrm{k}}$ via atomic force microscopy (AFM) observation. To obtain vertically oriented microphaseseparated structures, thin films ca. $50 \mathrm{~nm}$ in thickness were prepared by spin-coating onto Si substrates, and THF vapor annealing was applied to the films. ${ }^{75,76}$ The AFM height images of $\mathrm{SBS}_{27 \mathrm{k}}-\mathrm{LA}_{28 \mathrm{k}}$ and $\mathrm{SBS}_{27 \mathrm{k}}(c l)-\mathrm{LA}_{13 \mathrm{k}}$ thin films are shown in Fig. 8(a) and (b), respectively, where the dot patterns corresponding to the HEX structure oriented perpendicular to the film surface were observed. The insets show the 2D fast Fourier transform (FFT) profiles obtained from each height image. As expected, the LA cylinders embedded within the SBS matrix were more tightly packed in the $\operatorname{SBS}_{27 \mathrm{k}}(c l)-\mathrm{LA}_{13 \mathrm{k}}$ thin film than in the $\mathrm{SBS}_{27 \mathrm{k}}-\mathrm{LA}_{13 \mathrm{k}}$ thin film (Fig. 8(c)), strongly supporting our assumption about the structural change in HEX morphology after crosslinking (Fig. 6(b)). The $d_{\mathrm{C}-\mathrm{C}}$ values extracted from the 2D FFT profiles indeed decreased from $27.9 \mathrm{~nm}\left(\mathrm{SBS}_{27 \mathrm{k}}-\mathrm{LA}_{13 \mathrm{k}}\right)$ to $24.5 \mathrm{~nm}\left(\mathrm{SBS}_{27 \mathrm{k}}(c l)-\mathrm{LA}_{13 \mathrm{k}}\right)$ due to the intramolecular crosslinking. Thus, we confirmed the downsizing of the microphase-separated structures in the thin film state as well as in the bulk state. It is worth noting that a uniformly packed structure was observed in the thin film even after the intramolecular crosslinking (Fig. 8(b)) despite the decreased molecular mobility, as indicated by the ${ }^{1} \mathrm{H}$ NMR and DSC results. Overall, we successfully demonstrated feature size reduction as well as nanoscale organization of the crosslinkedlinear BCPs into a well-ordered morphology in the thin film state, supporting the applicability of the presented approach to lithographic technology.

\section{Conclusions}

We have successfully synthesized crosslinked-linear BCPs (SBS $(c l)$-LAs) from the linear-linear BCPs consisting of the crosslinkable SBS segment possessing pendant double bonds and the LA segment (SBS-LA), via the intramolecular olefin metathesis under highly diluted conditions. Morphological analyses of the obtained BCPs in the bulk state by SAXS measurement clearly revealed that the SBS $(c l)$-LAs had smaller $d$ values in their LAM and HEX morphologies as compared to the corresponding SBS-LAs, due to the restricted chain dimensions of the $\mathrm{SBS}(c l)$ segments. Importantly, the amount of $d$ decrease was controllable by varying the contents of the crosslinking sites, where the largest decrease (22\%) was achieved in LAM morphology with $c a$. $50 \%$ of the crosslinkable BS unit incorporated into the SBS block. Although the macrocyclic
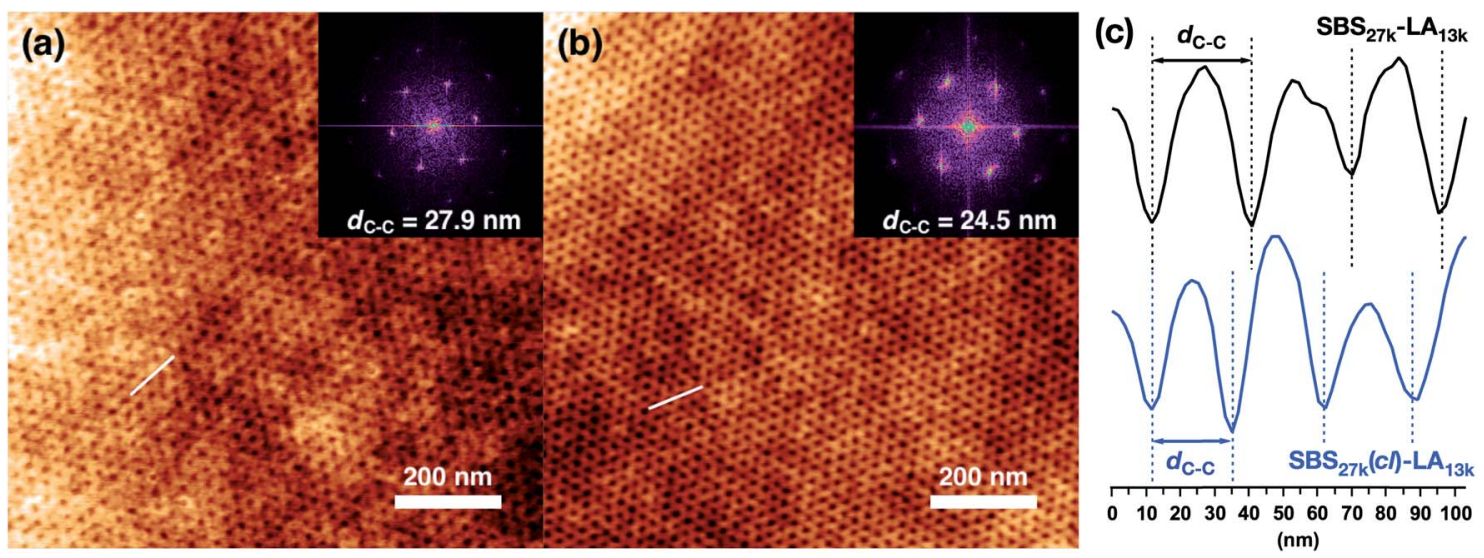

Fig. 8 AFM height images of (a) $\mathrm{SBS}_{27 \mathrm{k}}-\mathrm{LA}_{13 \mathrm{k}}$ and (b) $\mathrm{SBS}_{27 \mathrm{k}}(\mathrm{Cl})-\mathrm{LA}_{13 \mathrm{k}}$ thin films with thicknesses of 56 and $42 \mathrm{~nm}$, respectively. The insets show the 2D FFTs obtained from the height images. Scale bars are $200 \mathrm{~nm}$. (c) AFM height cross sectional images along the white lines in (a) (upper) and (b) (lower) 
or miktoarm architectures can effectively reduce the size of microphase-separated structures to some extent, further reduction in the $d$ value requires increasing the number of the cyclic units or the branching, which presents a synthetic challenge and practical limitations. In contrast, the currently reported intramolecular crosslinking approach could easily reduce the $d$ value further by simply controlling the crosslink density. We also confirmed the downsizing of the HEX morphology in the thin film state by AFM observation, and the uniformly packed structures were present even after the intramolecular crosslinking that reduced chain mobility of the crosslinked segment. To the best of our knowledge, this is the first experimental demonstration on how the intramolecular crosslinking of BCPs affects the microphase separation behaviors. Considering the fact that the sub-10 nm scale nanostructure was successfully downsized here and the crosslinkedlinear BCP could form a well-ordered structure in the thin film, the current approach is highly promising for the development of next-generation lithography. Moreover, the rutheniumcatalyzed olefin metathesis has excellent functional group tolerance, so this approach is expandable to a wide variety of BCPs. To produce even smaller microphase-separated structures, we are currently working on the synthesis and morphological analysis of crosslinked-crosslinked BCPs in which each block is separately crosslinked. Our methodology using this novel-shaped BCP should eventually contribute to remarkable advancements in not only lithography but also other nanomanufacturing applications, such as mesoporous filtering membranes and high-performance memory devices.

\section{Conflicts of interest}

There are no conflicts to declare.

\section{Acknowledgements}

This work was financially supported by the MEXT Grant-in-Aid for Research Activity Start-up (26888001), Grant-in-Aid for Young Scientists (B) (15K17862), Grant-in-Aid for Scientific Research (B) (16H04152), and Grant-in-Aid for Scientific Research on Innovative Areas "Hybrid Catalysis" (18H04639). K. W. was funded by a JSPS Fellowship for Young Scientists. T. I gratefully acknowledges the Nanotech CUPAL NRP program. The authors thank Prof. H. Ito (Hokkaido University, Japan) for his assistance with the AFM experiments.

\section{Notes and references}

1 C. Park, J. Yoon and E. L. Thomas, Polymer, 2003, 44, 67256760.

2 H.-C. Kim, S.-M. Park and W. D. Hinsberg, Chem. Rev., 2010, 110, 146-177.

3 J. K. Kim, S. Y. Yang, Y. Lee and Y. Kim, Prog. Polym. Sci., 2010, 35, 1325-1349.

4 A. Horechyy, B. Nandan, N. E. Zafeiropoulos, P. Formanek, U. Oertel, N. C. Bigall, A. Eychmüller and M. Stamm, Adv. Funct. Mater., 2013, 23, 483-490.
5 H.-Y. Hsueh, C.-T. Yao and R.-M. Ho, Chem. Soc. Rev., 2015, 44, 1974-2018.

6 M. Stefik, S. Guldin, S. Vignolini, U. Wiesner and U. Steiner, Chem. Soc. Rev., 2015, 44, 5076-5091.

7 C. M. Bates and F. S. Bates, Macromolecules, 2017, 50, 3-22.

8 C.-C. Hung, Y.-C. Chiu, H.-C. Wu, C. Lu, C. Bouilhac, I. Otsuka, S. Halila, R. Borsali, S.-H. Tung and W.-C. Chen, Adv. Funct. Mater., 2017, 27, 1-10.

9 M. P. Stoykovich, M. Müller, S. O. Kim, H. H. Solak, E. W. Edwards, J. J. de Pablo and P. F. Nealey, Science, 2005, 308, 1442-1446.

10 M. P. Stoykovich and P. F. Nealey, Mater. Today, 2006, 9, 2029.

11 M. Li and C. K. Ober, Mater. Today, 2006, 9, 30-39.

12 R. Ruiz, H. Kang, F. A. Detcheverry, E. Dobisz, D. S. Kercher, T. R. Albrecht, J. J. de Pablo and P. F. Nealey, Science, 2008, 321, 936-939.

13 J. Bang, U. Jeong, D. Y. Ryu, T. P. Russell and C. J. Hawker, Adv. Mater., 2009, 21, 4769-4792.

14 C. M. Bates, M. J. Maher, D. W. Janes, C. J. Ellison and C. G. Willson, Macromolecules, 2014, 47, 2-12.

15 A. Nunns, J. Gwyther and I. Manners, Polymer, 2013, 54, 1269-1284.

16 S.-J. Jeong, J. Y. Kim, B. H. Kim, H.-S. Moon and S. O. Kim, Mater. Today, 2013, 16, 468-476.

17 C.-C. Liu, E. Han, M. S. Onses, C. J. Thode, S. Ji, P. Gopalan and P. F. Nealey, Macromolecules, 2011, 44, 1876-1885.

18 J. Kwak, A. K. Mishra, J. Lee, K. S. Lee, C. Choi, S. Maiti, M. Kim and J. K. Kim, Macromolecules, 2017, 50, 68136818.

19 R. Nakatani, H. Takano, A. Chandra, Y. Yoshimura, L. Wang, Y. Suzuki, Y. Tanaka, R. Maeda, N. Kihara, S. Minegishi, K. Miyagi, Y. Kasahara, H. Sato, Y. Seino, T. Azuma, H. Yokoyama, C. K. Ober and T. Hayakawa, ACS Appl. Mater. Interfaces, 2017, 9, 31266-31278.

20 A. Legrain, G. Fleury, M. Mumtaz, C. Navarro, J. Arias-Zapata, X. Chevalier, I. Cayrefourcq and M. Zelsmann, ACS Appl. Mater. Interfaces, 2017, 9, 43043-43050.

21 L. Leibler, Macromolecules, 1980, 13, 1602-1617.

22 F. S. Bates and G. H. Fredrickson, Annu. Rev. Phys. Chem., 1990, 41, 525-557.

23 T.-Y. Lo, M. R. Krishnan, K.-Y. Lu and R.-M. Ho, Prog. Polym. Sci., 2018, 77, 19-68.

24 M. D. Rodwogin, C. S. Spanjers, C. Leighton and M. A. Hillmyer, ACS Nano, 2010, 4, 725-732.

25 J. D. Cushen, C. M. Bates, E. L. Rausch, L. M. Dean, S. X. Zhou, C. G. Willson and C. J. Ellison, Macromolecules, 2012, 45, 8722-8728.

26 M. J. Maher, C. T. Rettner, C. M. Bates, G. Blachut, M. C. Carlson, W. J. Durand, C. J. Ellison, D. P. Sanders, J. Y. Cheng and C. G. Willson, ACS Appl. Mater. Interfaces, 2015, 7, 3323-3328.

27 K. Aissou, M. Mumtaz, G. Fleury, G. Portale, C. Navarro, E. Cloutet, C. Brochon, C. A. Ross and G. Hadziioannou, Adv. Mater., 2015, 27, 261-265.

28 Y. Luo, D. Montarnal, S. Kim, W. Shi, K. P. Barteau, C. W. Pester, P. D. Hustad, M. D. Christianson, 
G. H. Fredrickson, E. J. Kramer and C. J. Hawker, Macromolecules, 2015, 48, 3422-3430.

29 W.-S. Young and T. H. Epps, Macromolecules, 2009, 68, 26722678.

30 S. Park, D. H. Lee, J. Xu, B. Kim, S. W. Hong, U. Jeong and T. P. Russell, Science, 2009, 323, 1030.

31 Z. Sun, Z. Chen, W. Zhang, J. Choi, C. Huang, G. Jeong, E. B. Coughlin, Y. Hsu, X. Yang, K. Y. Lee, D. S. Kuo, S. Xiao and T. P. Russell, Adv. Mater., 2015, 27, 4364-4370.

32 J. D. Cushen, I. Otsuka, C. M. Bates, S. Halila, S. Fort, C. Rochas, J. A. Easley, E. L. Rausch, A. Thio, R. Borsali, C. G. Willson and C. J. Ellison, ACS Nano, 2012, 6, 3424-3433.

33 I. Otsuka, S. Tallegas, Y. Sakai, C. Rochas, S. Halila, S. Fort, A. Bsiesy, T. Baron and R. Borsali, Nanoscale, 2013, 5, 26372641.

34 Y. Sakai-Otsuka, S. Zaioncz, I. Otsuka, S. Halila, P. Rannou and R. Borsali, Macromolecules, 2017, 50, 3365-3376.

35 T. Isono, B. J. Ree, K. Tajima, R. Borsali and T. Satoh, Macromolecules, 2018, 51, 428-437.

36 J. E. Poelma, K. Ono, D. Miyajima, T. Aida, K. Satoh and C. J. Hawker, ACS Nano, 2012, 6, 10845-10854.

37 T. Isono, I. Otsuka, Y. Kondo, S. Halila, S. Fort, C. Rochas, T. Satoh, R. Borsali and T. Kakuchi, Macromolecules, 2013, 46, 1461-1469.

38 W. Shi, Y. Tateishi, W. Li, C. J. Hawker, G. H. Fredrickson and E. J. Kramer, ACS Macro Lett., 2015, 4, 1287-1292.

39 H. Minehara, L. M. Pitet, S. Kim, R. H. Zha, E. W. Meijer and C. J. Hawker, Macromolecules, 2016, 49, 2318-2326.

40 K. Yue, C. Liu, M. Huang, J. Huang, Z. Zhou, K. Wu, H. Liu, Z. Lin, A.-C. Shi, W.-B. Zhang and S. Z. D. Cheng, Macromolecules, 2017, 50, 303-314.

41 N. Hosono, M. A. J. Gillissen, Y. Li, S. S. Sheiko, A. R. A. Palmans and E. W. Meijer, J. Am. Chem. Soc., 2013, 135, 501-510.

42 G. M. ter Huurne, M. A. J. Gillissen, A. R. A. Palmans, I. K. Voets and E. W. Meijer, cJ. Am. Chem. Soc., 2015, 48, 3949-3956.

43 Y. Liu, T. Pauloehrl, S. I. Presolski, L. Albertazzi, A. R. A. Palmans and E. W. Meijer, J. Am. Chem. Soc., 2015, 137, 13096-13105.

44 O. Altintas, M. Artar, G. ter Huurne, I. K. Voets, A. R. A. Palmans, C. Barner-Kowollik and E. W. Meijer, Macromolecules, 2015, 48, 8921-8932.

45 A. Sanchez-Sanchez, S. Akbari, A. J. Moreno, F. L. Verso, A. Arbe, J. Colmenero and J. A. Pomposo, Macromol. Rapid Commun., 2013, 34, 1681-1686.

46 I. Perez-Baena, I. Asenjo-Sanz, A. Arbe, A. J. Moreno, F. L. Verso, J. Colmenero and J. A. Pomposo, Macromolecules, 2014, 47, 8270-8280.

47 A. Sanchez-Sanchez, D. A. Fulton and J. A. Pomposo, Chem. Commun., 2014, 50, 1871-1874.

48 S. Basasoro, M. Gonzalez-burgos, A. J. Moreno, F. L. Verso, A. Arbe, J. Colmenero and J. A. Pomposo, Macromol. Rapid Commun., 2016, 37, 1060-1065.

49 T. Terashima, T. Sugita, K. Fukae and M. Sawamoto, Macromolecules, 2014, 47, 589-600.
50 K. Matsumoto, T. Terashima, T. Sugita, M. Takenaka and M. Sawamoto, Macromolecules, 2016, 49, 7917-7927.

51 E. Harth, B. Van Horn, V. Y. Lee, D. S. Germack, C. P. Gonzales, R. D. Miller and C. J. Hawker, J. Am. Chem. Soc., 2002, 124, 8653-8660.

52 C. F. Hansell, A. Lu, J. P. Patterson and R. K. O'Reilly, Nanoscale, 2014, 6, 4102-4107.

53 J. B. Beck, K. L. Killops, T. Kang, K. Sivanandan, A. Bayles, M. E. Mackay, K. L. Wooley and C. J. Hawker, Macromolecules, 2009, 42, 5629-5635.

54 C. Song, L. Li, L. Dai and S. Thayumanavan, Polym. Chem., 2015, 6, 4828-4834.

55 O. Altintas, J. Willenbacher, K. N. R. Wuest, K. K. Oehlenschlaeger, P. Krolla-Sidenstein, H. Gliemann and C. Barner-Kowollik, Macromolecules, 2013, 46, 80928101.

56 J. Willenbacher, K. N. R. Wuest, J. O. Mueller, M. Kaupp, H.-A. Wagenknecht and C. Barner-Kowollik, ACS Macro Lett., 2014, 3, 574-579.

57 K. N. R. Wuest, H. Lu, D. S. Thomas, A. S. Goldmann, M. H. Stenzel and C. Barner-Kowollik, ACS Macro Lett., 2017, 6, 1168-1174.

58 T. S. Fischer, S. Spann, Q. An, B. Luy, M. Tsotsalas, J. P. Blinco, H. Mutlu and C. Barner-Kowollik, Chem. Sci., 2018, 9, 4696-4702.

59 A. S. Zalusky, R. Olayo-Valles, C. J. Taylor and M. A. Hillmyer, J. Am. Chem. Soc., 2001, 123, 1519-1520.

60 A. S. Zalusky, R. Olayo-Valles, J. H. Wolf and M. A. Hillmyer, J. Am. Chem. Soc., 2002, 124, 12761-12773.

61 R. Olayo-Valles, M. S. Lund, C. Leighton and M. A. Hillmyer, J. Mater. Chem., 2004, 14, 2729-2731.

62 R. Olayo-Valles, S. Guo, M. S. Lund, C. Leighton and M. A. Hillmyer, Macromolecules, 2005, 38, 10101-10108.

63 A. Baruth, M. Rodwogin, A. Shankar, M. A. Torija, M. J. Erickson, M. A. Hillmyer and C. Leighton, ACS Appl. Mater. Interfaces, 2011, 3, 3472-3481.

64 A. Baruth, M. Seo, C. H. Lin, K. Walster, A. Shankar, M. A. Hillmyer and C. Leighton, ACS Appl. Mater. Interfaces, 2014, 6, 13770-13781.

65 M. E. Vanderlaan and M. A. Hillmyer, Macromolecules, 2016, 49, 8031-8040.

66 H. Zhang and E. Ruckenstein, Macromolecules, 1999, 32, 5495-5500.

67 K. Watanabe, R. Tanaka, K. Takada, M.-J. Kim, J.-S. Lee, K. Tajima, T. Isono and T. Satoh, Polym. Chem., 2016, 7, 4782-4792.

68 R. Tanaka, K. Watanabe, T. Yamamoto, K. Tajima, T. Isono and T. Satoh, Polym. Chem., 2017, 8, 3647-3656.

69 D. Mecerreyes, V. Lee, C. J. Hawker, J. L. Hedrick, A. Wursch, W. Volksen, T. Magbitang, E. Huang and R. D. Miller, Adv. Mater., 2001, 13, 204-208.

70 J. He, L. Tremblay, S. Lacelle and Y. Zhao, Soft Matter, 2011, 7, 2380.

71 J. Rubio-Cervilla, F. Barroso-Bujans and J. A. Pomposo, Macromolecules, 2016, 49, 90-97.

72 F. Wang, H. Pu, M. Jin and D. Wan, Macromol. Rapid Commun., 2016, 37, 330-336. 
73 J. Zhang, G. Gody, M. Hartlieb, S. Catrouillet, J. Moffat and S. Perrier, Macromolecules, 2016, 49, 8933-8942.

74 T. Hashimoto, H. Tanaka and H. Hasegawa, Macromolecules, 1985, 18, 1864-1868.
75 M. Vayer, M. A. Hillmyer, M. Dirany, G. Thevenin, R. Erre and C. Sinturel, Thin Solid Films, 2010, 518, 3710-3715.

76 M. Dirany, P. Lacroix-Desmazes, M. Vayer, R. Erre, B. Boutevin and C. Sinturel, J. Appl. Polym. Sci., 2011, 122, 2944-2951. 